\title{
Fuzzy Control Design for a Class of Nonlinear Network Control System: Helicopter Case Study
}

\author{
P.Q. Reyes, J.O. Arjona, E.M. Monroy, H.B. Pérez, A.D. Chavesti
}

\author{
P. Quiñones-Reyes \\ Instituto Tecnológico de Jiquilpan \\ Carr. Nac., S/N Km. 202, CP 59510, \\ Jiquilpan, Michoacán, México. \\ J. Ortega-Arjona, E. Méndez-Monroy, \\ H. Benítez-Pérez, A. Durán-Chavesti \\ Universidad Nacional Autónoma de México \\ Apdo. Postal 20-726, Admón. 20, \\ Del. A. Obregón, México D. F., CP. 01000. \\ polbond@hotmail.com,jloa@ciencias.unam.mx, \\ $\{$ hector,chavesti\}@uxdea4.iimas.unam.mx
}

\begin{abstract}
This paper presents a fuzzy control approach to a helicopter MIMO nonlinear system, implemented on a Networked Control System, as case study. For this, a hardware-in-the-Loop implementation is developed using several multi-channel A/D Cards, integrated to a computer network system. Variant time delays are considered over Ethernet and CANBUS networks. Fuzzy logic is used to deal with the complexity of the integrated computer network as well as with the dynamics of the system. Two fuzzy logic control systems are coupled for both signals of the helicopter case study: yaw and pitch. Both these tend to concentrate around desired references, considering variant time delays.
\end{abstract}

Keywords: fuzzy control, networked control systems.

\section{Introduction}

Reconfiguration is a transition that modifies the structure of a system so it changes its representation of states. Here, it is used as a feasible approach for fault isolation, and also, it is a response to time delay modification.

In control systems, several modelling strategies for managing time delay within control laws have been studied by different research groups. Nilsson [16] proposes the use of a time delay scheme integrated to a reconfigurable control strategy, based on a stochastic methodology. Jiang [12] describe how time delays are used as uncertainties, which modify pole placement of a robust control law. Izadi present an interesting case of fault tolerant control approach related to time delay coupling. Blanke [7] study reconfigurable control from the point of view of structural modification, establishing a logical relation between dynamic variables and the respective faults. Thompson [17] and Benítez-Pérez [4] consider that reconfigurable control strategies perform a combined modification of system structure and dynamic response, and thus, this approach has the advantage of bounded modifications over system response. Recent approximations are presented by Dai, which allow a reasonable but static approximation for time variable strategy. Also, Kim [20] have followed a Maximum Allowable Time Delay (MADB), where complex task behaviour is permitted as long as MADB is preserved [22] [23]. 
The approach here makes use of a case study that takes time delays due to communication as deterministic measured variables. For this, a Fuzzy Control law [1] is used, where time delays result from the deterministic reconfiguration of communications due to a scheduling algorithm. Fuzzy Control is used for managing extended horizons from system inputs and outputs, to determine several scenarios modified by time delays. Recent results encourage this approximation, as shown in Benítez-Perez [5] [6].

For experimental purposes, the following considerations are taken:

1. Time delays are bounded.

2. The combination tends to be globally stable.

The objective of this paper is to present the design of a fuzzy control strategy developed from the time delay knowledge, as well as computer network behaviour considering communication amongst nodes for a helicopter case study. The novelty is to propose a Fuzzy Control [24] [25] for Network Control System (NCS) based on the defined communication network and variant time delays.

Present approach makes use of time delays due to communication as deterministic measured variables, defined by previous knowledge of computer network. In here, control law views time delays as a result of bounded communications based upon scheduling algorithm.

A basic consideration for this approach is that time delays are bounded to MADB. The main reason for these is the behavior of computer network as well as node processing time. However, in order to integrate this variable as global time delay $\left(\Delta \mathrm{t}_{*}\right)$, it is necessary to consider its nominal value. This is presented as a percentage: 0\% refers to the current time delay, and 100\% represents extreme time delays. Hence, this value is any value produced as time delay less than or equal to total sampling period.

Having defined global time delays as its nominal value, the fuzzy control structure is proposed as shown in Figure 1.

Fuzzy control is chosen here for implementing a gain-scheduler controller, on contrary of Smith's predictor [18], since it has a smooth transition between scenarios. Furthermore, the chosen operating points are the reference elements of proposed fuzzy control. Thus, any degradation from time delays would degrade the control law, however keeping a stable response from the plant. Time delay degradation is bounded from communication protocol, as explained by [13].

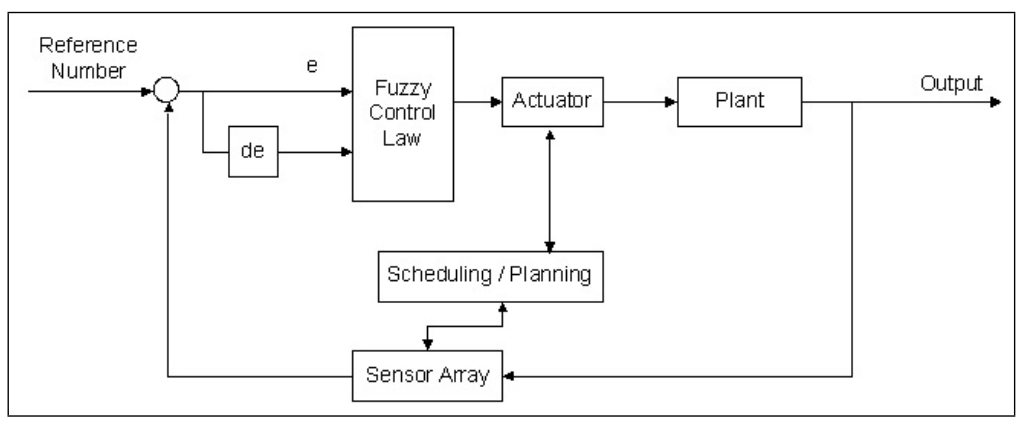

Figure 1: Fuzzy Control Structure. 
Notice that the current approach follows a Mamdani strategy [18] rather than a Takagi Sugeno (TKS) [1] for the implementation of the fuzzy control. The development of a TKS strategy is considered as a future work, aiming for integrating time delays into a subsequent part of the fuzzy control rules.

The fuzzy control law for a fault free scenario is presented in Figure 2, based on [18]. Membership functions are Gaussian distributions, where $e$ has six membership functions (PB, PM, PS, NS, NM, NB), and de has 6 membership functions (PB, PM, PS, NS, NM, NB). The output variable has eight membership functions (PB, PM, PS, PZ, NZ, NS, NM, NB). An additional variable, named Current Nominal Time Delay (CNTD), has three membership functions (N, Z, $\mathrm{P})$.

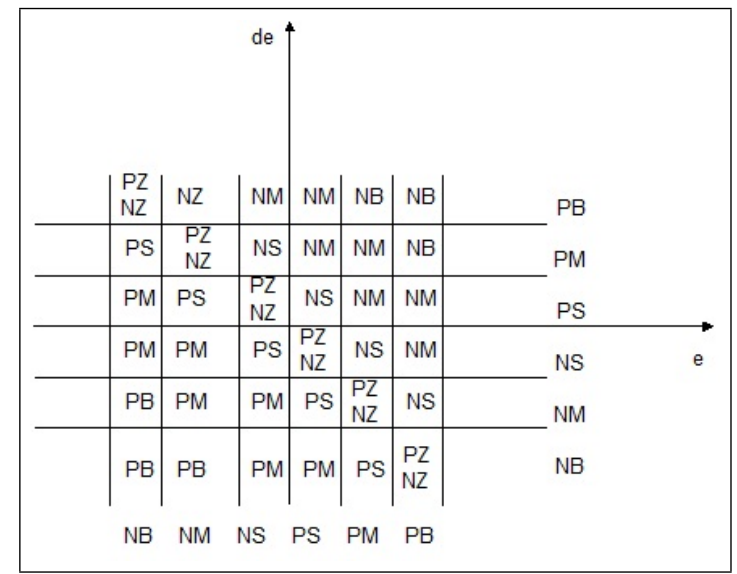

Figure 2: Classical Structure for Fuzzy Control Law

Notice that this implementation is common for fuzzy control design, however, here fuzzy control design focuses on the strategy of the control law due to the communication in the computer network, as well as the consequent time delays. These time delays are measurable and bounded, according to previous knowledge of computer network, based on a finite state machine that selects when valid strategies take place. Here, the scheduling approximation is the inherent EDF algorithm [14] with certain lost data. The aim is to study how this transition is carried out when using a Fuzzy Mamdani approach [1], based on a NCS. Particularly, for the actual NCS, the communication network strongly affects the dynamics of the system, expressed as a time variance that exposes a nonlinear behaviour. Such nonlinearity is addressed by incorporating time delays. From real-time system theory, it is known that time delays are bounded even in the case of causal modifications due to external effects [15]. Using this representation, time delays are counted using simple addition, as described as follows.

\section{Case Study and Experimental Setup}

The case study here is a Helicopter MIMO system, integrated to a computer network as shown in Figure 3 [21]. It is integrated by three A/D Cards: an AD512 card is the interface of joystick, acting as moving reference; an AD612 card is the interface of actuators yaw and pitch; and a Q4 card is used for sampling the information from two encoders which sense yaw and pitch information from the movement. Two networks are used for this case study: an Ethernet network at $10 / 100 \mathrm{Mhz}$, and a CAN network at $1 \mathrm{Mbit} / \mathrm{s}$. For experimental purposes, the controller node works as well as gateway for both databuses. 


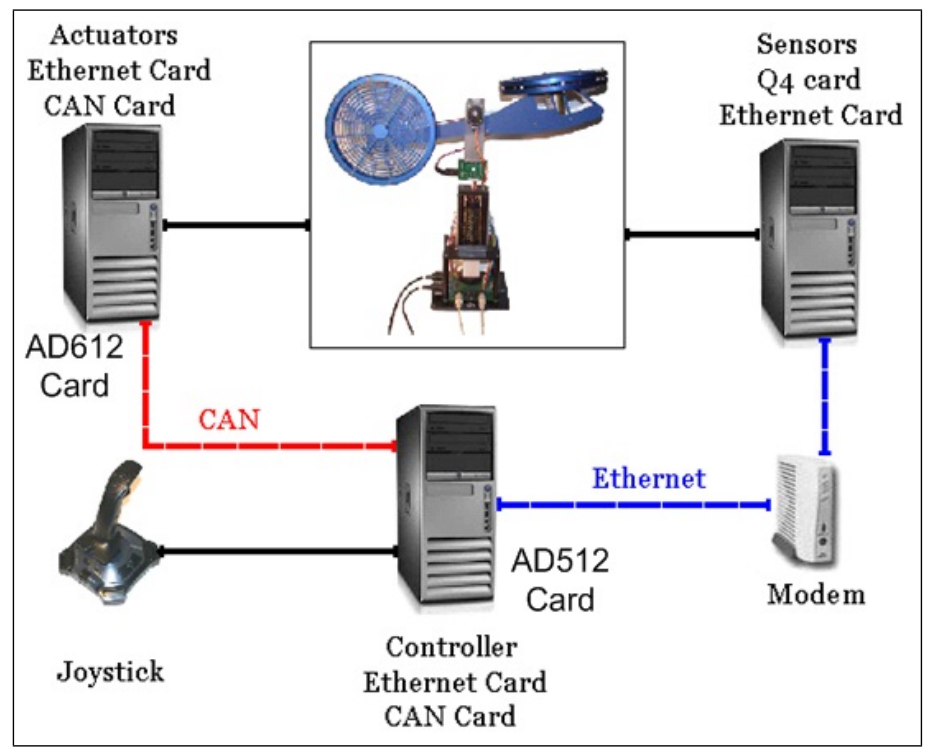

Figure 3: Helicopter MIMO system for the case study

While the description of the helicopter is beyond the scope of this paper, a brief description is provided here. However, further information can be found in the original Quanser [21] documentation. The Quanser 2 DOF Helicopter consists of a helicopter model mounted on a fixed base with two propellers that are driven by DC motors. The front propeller controls the elevation of the helicopter nose about the pitch axis and the back propeller controls the side-to-side motions of the helicopter about the yaw axis. The pitch and yaw angles are measured using high-resolution encoders. The two degrees of freedom helicopter pivots about the pitch axis by angle $\theta$ and about the yaw axis by angle $\psi$. The pitch is defined positive when the nose of the helicopter goes up and the yaw is defined positive for a clockwise rotation. Table 1 lists the various lengths, masses, and moment of inertias associated with this helicopter model.

\begin{tabular}{|l|l|l|l|}
\hline Variable & Description & Value & Unit \\
\hline$B e q, p$ & Equivalent viscous damping about pitch axis. & 0.800 & $\mathrm{~N} / \mathrm{V}$ \\
\hline$B e q, y$ & Equivalent viscous damping about yaw axis. & 0.318 & $\mathrm{~N} / \mathrm{V}$ \\
\hline$J e q, p$ & Total moment of inertia about pitch pivot. & 0.0384 & $\mathrm{~kg} \cdot \mathrm{m}^{2}$ \\
\hline$J e q, y$ & Total moment of inertia about yaw pivot. & 0.0384 & $\mathrm{~kg} . \mathrm{m}^{2}$ \\
\hline$K p p$ & $\begin{array}{l}\text { Thrust torque constant acting on pitch axis from pitch } \\
\text { motor/propeller. }\end{array}$ & 0.204 & $\mathrm{~N} . \mathrm{m} / \mathrm{V}$ \\
\hline Kpy & $\begin{array}{l}\text { Thrust torque constant acting on pitch axis from yaw } \\
\text { motor/propeller. }\end{array}$ & 0.0068 & $\mathrm{~N} . \mathrm{m} / \mathrm{V}$ \\
\hline Kyp & $\begin{array}{l}\text { Thrust torque constant acting on yaw axis from pitch } \\
\text { motor/propeller. }\end{array}$ & 0.0219 & $\mathrm{~N} \cdot \mathrm{m} / \mathrm{V}$ \\
\hline Kyy & $\begin{array}{l}\text { Thrust torque constant acting on yaw axis from yaw mo- } \\
\text { tor/propeller. }\end{array}$ & 0.072 & $\mathrm{~N} \cdot \mathrm{m} / \mathrm{V}$ \\
\hline$l c m$ & $\begin{array}{l}\text { Center-of-mass length along helicopter body from pitch } \\
\text { axis. }\end{array}$ & 0.186 & $\mathrm{Cm}$ \\
\hline mheli & Total moving mass of the helicopter. & 1.3872 & $\mathrm{Kg}$ \\
\hline
\end{tabular}

Table 1: Helicopter specifications and model parameters. 
The linear state-space model of the helicopter is given by Equation 1. Notice that the nonlinear equations of motion are considered linear about the quiescent point $\left(\theta_{0}=0, \psi_{0}=0, \theta_{0}=0\right.$, $\left.\psi_{0}=0\right)$. Substituting the state $\mathrm{x}=[\theta, \psi, \theta, \psi]$ and solving for $\mathrm{x}$ :

$$
x=\left[\begin{array}{cccccc}
0 & 0 & 1 & 0 & 0 & 0 \\
0 & 0 & 0 & 1 & 0 & 0 \\
0 & 0 & -\frac{B_{p}}{J_{e q, p}+m_{\text {heli }} l_{c m}^{2}} & 0 & 0 & 0 \\
0 & 0 & 0 & -\frac{B_{y}}{J_{e q, y}+m_{h e l i} l_{c m}^{2}} & 0 & 0 \\
1 & 0 & 0 & 0 & 0 & 0 \\
0 & 1 & 0 & 0 & 0 & 0
\end{array}\right] x+\left[\begin{array}{cc}
0 & 0 \\
0 & 0 \\
\frac{K_{p p}}{J_{e q, p}+m_{h e l i} l_{c m}^{2}} & \frac{K_{y p}}{\frac{K_{e q, p}+m_{h e l i} l_{c m}^{2}}{J_{e q, y}+m_{h e l i} l_{c m}^{2}}} \\
0 & \frac{K_{y y}}{J_{e q, y}+m_{h e l i} l_{c m}^{2}} \\
0 & 0 \\
0
\end{array}\right] u
$$

$$
y=\left[\begin{array}{llllll}
1 & 0 & 0 & 0 & 0 & 0 \\
0 & 1 & 0 & 0 & 0 & 0 \\
0 & 0 & 1 & 0 & 0 & 0 \\
0 & 0 & 0 & 1 & 0 & 0 \\
0 & 0 & 0 & 0 & 1 & 0 \\
0 & 0 & 0 & 0 & 0 & 1
\end{array}\right] x
$$

In order to establish an experimental setup, several conditions nave to be taken into account. For example, the communication network frequencies for Ethernet and CANBUS are set $10 / 100 \mathrm{Mhz}$ and $1 \mathrm{Mbit} / \mathrm{s}$, respectively. Moreover, the derivative boundary for pitch is -0.3 to 0.3 . The rest of the boundaries are shown Table 2 .

\begin{tabular}{|l|c|c|c|}
\hline & Maximum Value & Minimum Value & Standard Deviations \\
\hline Derivative Value & -0.3 & 0.3 & \\
\hline Error Value & -0.25 & 0.25 & \\
\hline Control Value & 0 & 25 & 0.12 \\
\hline Derivative Center & $-0.3-0.200 .20 .3$ & 0.1 \\
\hline Error Centers & $-0.25-0.0500 .050 .25$ & \\
\hline $\begin{array}{l}\text { Names of current } \\
\text { membership func- } \\
\text { tions }\end{array}$ & CMP CP CM CG CMG & \\
\hline
\end{tabular}

Table 2: Signal Characteristics of pitch.

Table 3 shows the related consequent matrix for pitch signal. This is coupled following control law for yaw signal, where time delays are affecting both control laws.

\begin{tabular}{|l|c|c|c|c|c|}
\hline Error-Derv & MP & P & M & G & MG \\
\hline $\mathrm{mp}$ & $\mathrm{CP}$ & $\mathrm{CP}$ & $\mathrm{CP}$ & $\mathrm{CM}$ & $\mathrm{CM}$ \\
\hline $\mathrm{p}$ & $\mathrm{CP}$ & $\mathrm{CP}$ & $\mathrm{CM}$ & $\mathrm{CM}$ & $\mathrm{CM}$ \\
\hline $\mathrm{m}$ & $\mathrm{CP}$ & $\mathrm{CM}$ & $\mathrm{CM}$ & $\mathrm{CM}$ & $\mathrm{CG}$ \\
\hline $\mathrm{g}$ & $\mathrm{CM}$ & $\mathrm{CM}$ & $\mathrm{CM}$ & $\mathrm{CG}$ & $\mathrm{CG}$ \\
\hline $\mathrm{mg}$ & $\mathrm{CM}$ & $\mathrm{CM}$ & $\mathrm{CG}$ & $\mathrm{CG}$ & $\mathrm{CG}$ \\
\hline
\end{tabular}

Table 3: Membership relationships amongst consequent parts for pitch signal. 
Table 4 shows the main characteristics of control approach for the yaw signal. Notice that the numerical values tend to be different to those related to pitch control law. This is basically due to dynamic conditions of yaw signal.

\begin{tabular}{|l|c|c|c|}
\hline & Maximum Value & Minimum Value & Standard Deviations \\
\hline Derivative Value & -0.2 & 0.2 & \\
\hline Error Value & -0.5 & 0.5 & \\
\hline Control Value & -20 & 15 & 0.08 \\
\hline Derivative Center & $-0.2-0.100 .10 .2$ & 0.25 \\
\hline Error Centers furrent & $-0.25-0.12500 .1250 .25$ & \\
\hline $\begin{array}{l}\text { Names of curme } \\
\text { membership func- } \\
\text { tions }\end{array}$ & PMP PP PG PMG & \\
\hline
\end{tabular}

Table 4: Signal Characteristics of yaw.

Table 5 shows the matrix for yaw signal. This is considerable different from pitch due to dynamic response of the plant.

\begin{tabular}{|l|c|c|c|c|c|}
\hline $\begin{array}{l}\text { Error- } \\
\text { Derv }\end{array}$ & MP & P & M & G & MG \\
\hline Mp & PMG & PMG & PMG & PMG & PMG \\
\hline $\mathrm{p}$ & PMG & PMG & PG & PG & PG \\
\hline $\mathrm{m}$ & PM & PM & PM & PM & PM \\
\hline $\mathrm{g}$ & PP & PP & PP & PP & PP \\
\hline $\mathrm{mg}$ & PP & PP & PP & PP & PMP \\
\hline
\end{tabular}

Table 5: Membership relationships amongst consequent parts for yaw signal.

Now for both signals, the Mamdani integration is defined in Eqn 2:

$$
\begin{gathered}
u=\frac{\sum_{j=1}^{r} \alpha_{j} \beta_{j}}{\sum_{j=1}^{r} \alpha_{j}} \\
r=m x n \\
\alpha_{j}=\gamma_{m} \gamma_{n} \\
j=1 \ldots m x n \\
m=1 \ldots M \\
n=1 \ldots N \\
\gamma_{i}=\exp \left(-\left(\frac{x-c_{i}}{\sigma_{i}}\right)^{2}\right)
\end{gathered}
$$

where:

- $c_{i}$ are the centers of the Gaussians

- $\sigma_{i}$ are the standard deviations of the Gaussians.

- $m$ is the total number of Gaussians per error

- $n$ is the total number of Gaussians per error derivatives, and 
- $\beta_{j}$ is the group control centers

Figure 4 presents the control surface for pitch signal. This surface tends to have smooth transitions between rules and consequent parts. It has a local valley due to delay interaction and error. This response is reflected on error and derivative conversion.

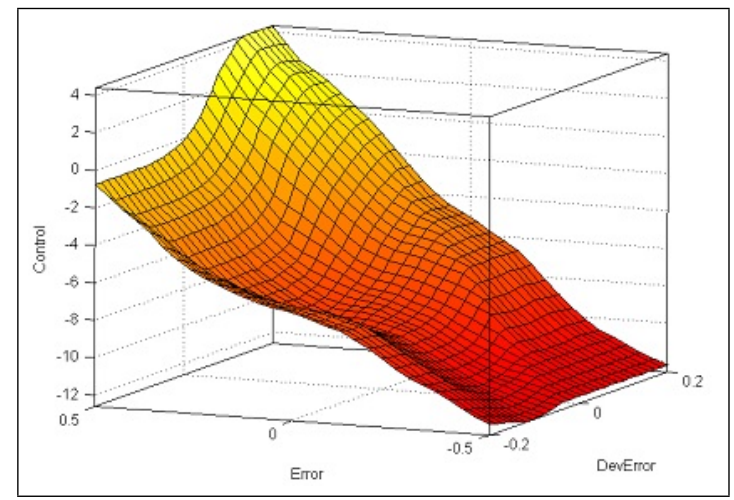

Figure 4: Control surface for pitch signal.

Figure 5 shows the control surface for the yaw signal. This tends to be more accurate in terms of formal fuzzy transitions, where only one small local valley exists.

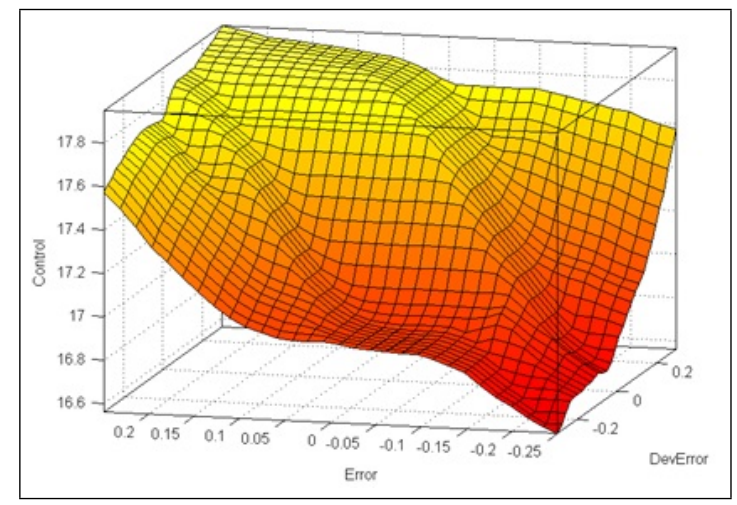

Figure 5: Control signal for yaw signal.

In both resulting surfaces, these tend to be smaller at negative error and derivative error values. On the contrary biggest values are related to both positive values (error and derivative respectively).

\section{Experimental Results}

Current time delays are bounded to normal representation as shown in Fig. 6. Where the delays are mainly considered as a result of communication media following Fig. 3.

The current experimental results show how the Helicopter MIMO case study adequately performs during time variant conditions. Considering an experimental execution of 50 seconds, several results show that, for instance, current error of yaw signal (Figure 7.a) presents a bounded response from 5 seconds onwards, while its derivative (Figure 7.b) tends to be almost zero, even in the case of change perturbation around 5 seconds. 


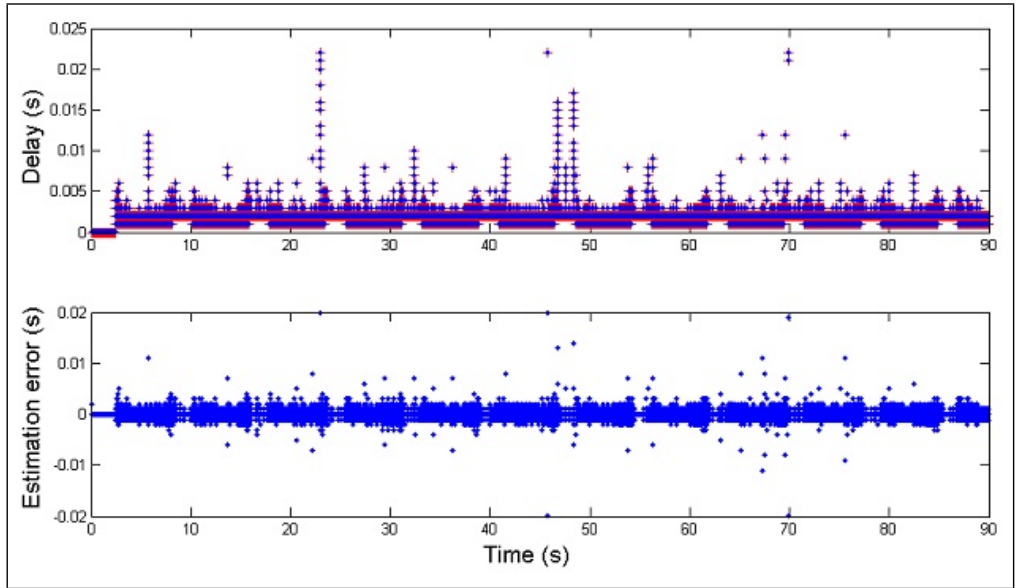

Figure 6: Communication Time Delays and the related Estimation Error.

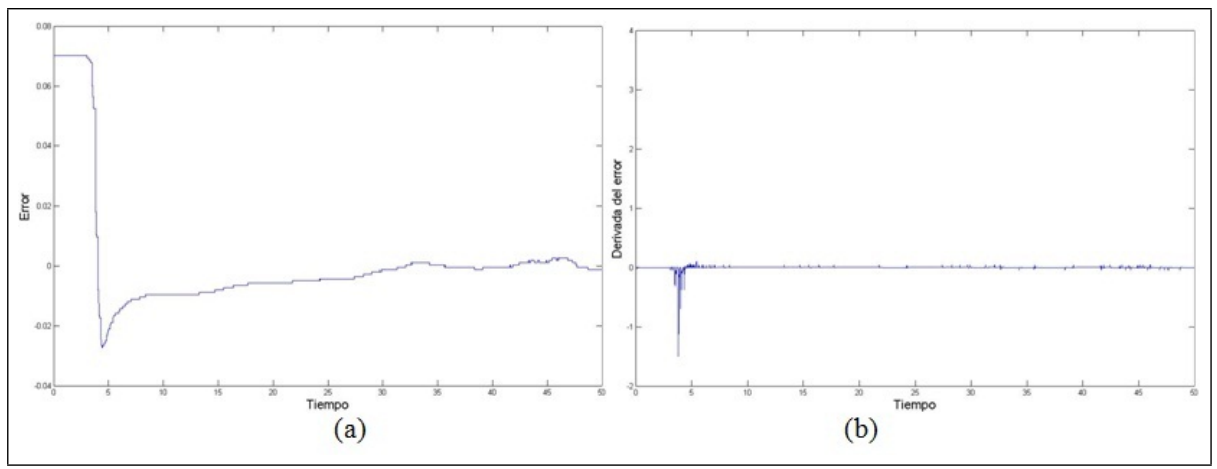

Figure 7: Error response for yaw signal. 
Figure 8 shows the control response for the yaw signal. It is a bounded response, where several glitches are spotted. These result from loosing data from the Ethernet network. Such a behaviour is not the actual delay from computer network, but it is an inherent feature of the Ethernet computer network.

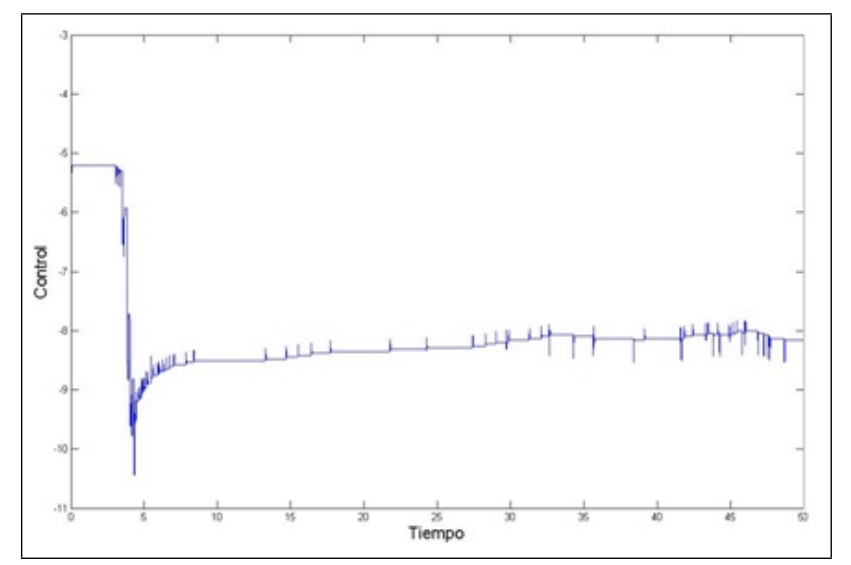

Figure 8: Control response for yaw signal.

Figure 9 presents a not-smooth transition between error and its derivative, due to local valley shown at Figure 4. Although system response is feasible for the current combination, it tends to have drastic, undesirable jumps.

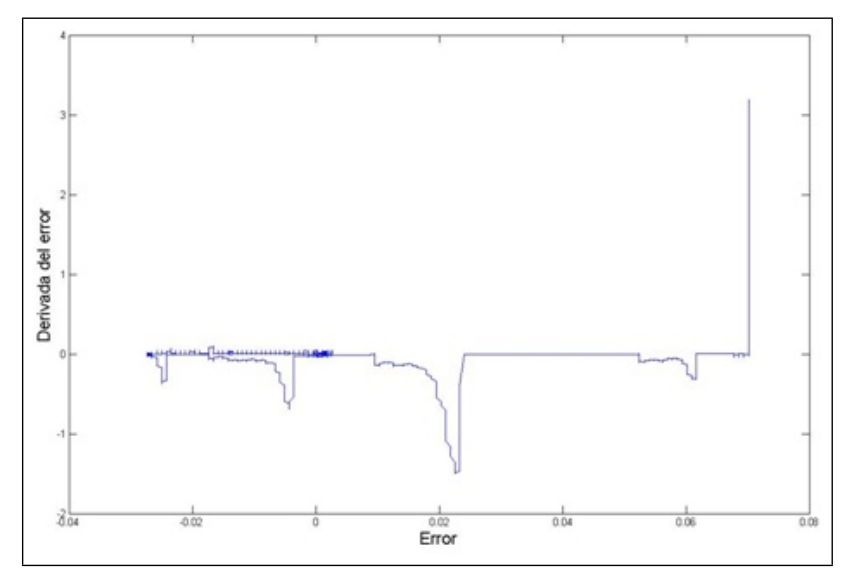

Figure 9: Error vs derivative of error response.

Regarding the pitch signal error, the response tends to be smooth and bounded. There is an inherent oscillation at error response (Figure 10.a), which results of slight movements from the joystick. The related derivative (Figure 10.b) reflects the bounded responses with some glitching.

Figure 11 shows the control response, presenting a similar behaviour, where glitches are present. These glitches result from loosing data in the communication network. 


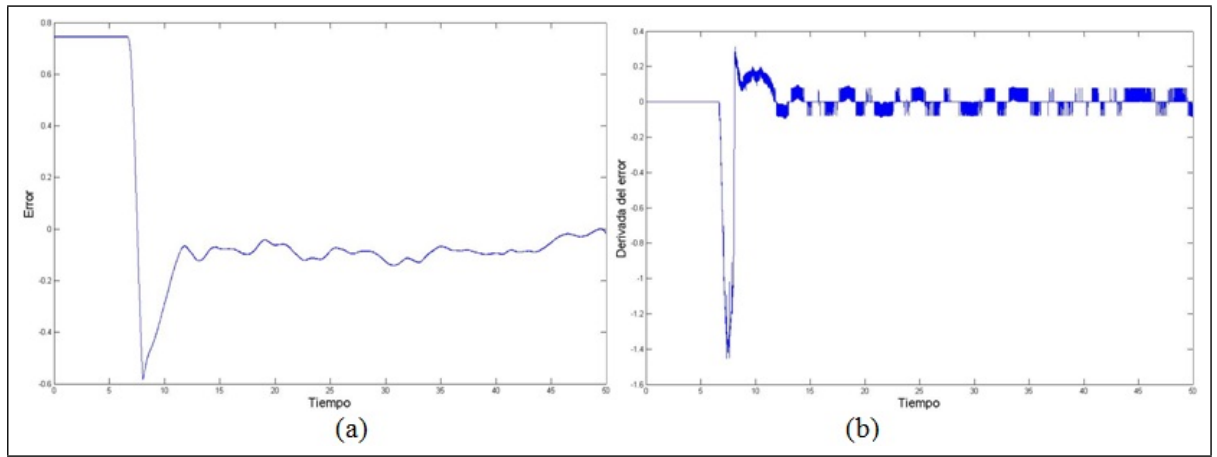

Figure 10: Error response for pitch signal.

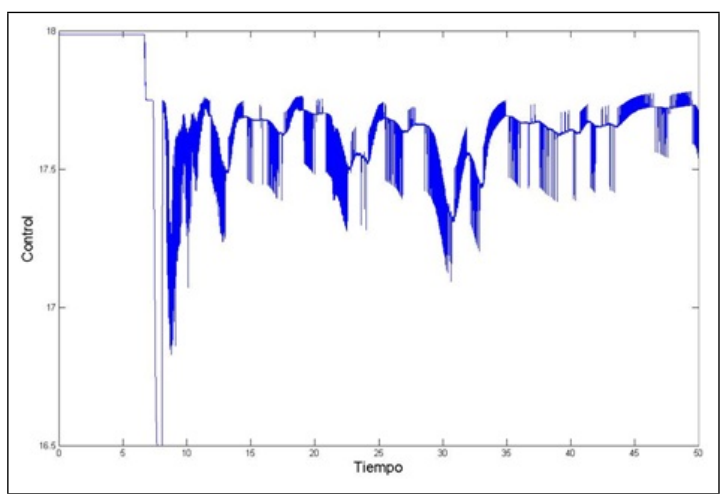

Figure 11: Control response for pitch signal.

Figure 12 shows a common response between error and derivative of error as convergence signal.

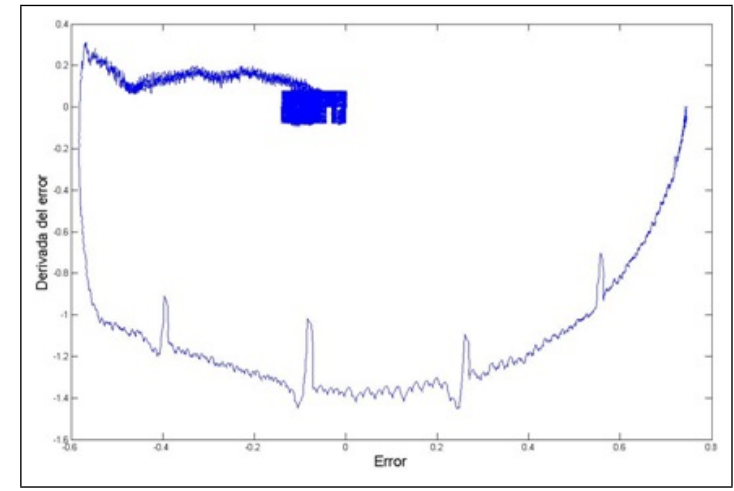

Figure 12: Error vs derivative of error response for pitch signal. 


\section{Concluding Remarks}

This paper presents an approach for the integration of two fuzzy logic controllers, in order to perform control under time variant conditions. These two techniques are applied in parallel. Although there is no formal verification for this sequence, it has been adopted since Mamdami approximation provides stable conditions for control reconfiguration. Moreover, the use of a real-time testbed to approve or disapprove changes on the behaviour of a computer network allows bounding time delays during a specific time frame. This local time delay allows the design of a control law, capable to cope with new conditions. Hardware-in-the-loop implementation is feasible, since complex integration through computer network as well as real-time Operating systems are integrated through bounded time delays

\section{Acknowledgements}

The authors would like to thank the financial support of DISCA-IIMAS-UNAM, and UNAMPAPIIT (IN103310-3), PICCO 10-53, Mexico in connection with this work.

\section{Bibliography}

[1] J. Abonyi, Fuzzy Model Identification for Control, Birkhd'z"user, 2003

[2] L. Almeida, P. Pedreiras and J. A.-Fonseca, The FTT-CAN Protocol: Why and How, IEEE Transactions on Industrial Electronics, 49(6):1189-1201, 2002

[3] H. Benítez-Pérez and F. García-Nocetti, Switching Fuzzy Logic Control for a Reconfigurable System Considering Communication Time Delays, Proceedings, CDROM, European Control Conference, ECC 03 September, 2003

[4] H. Benítez-Pérez and F. García-Nocetti, Reconfigurable Distributed Control, Springer Ver$\operatorname{lag}, 2005$

[5] H. Benítez-Pérez, Real-Time Distributed Control A Diverse Approach for Nonlinear Problem, Nonlinear Analysis: Hybrid Systems and Applications, doi:10.1016/j.nahs.2006.06.004, Vol 2/2 pp 474-490, Junio 2008

[6] H. Benítez-Pérez, J. S.-Gonzalez, F. C.-Flores and F. García-Nocetti, Fault Classification for a Class of Time Variable Systems by using a group of three ART2 Networks, International Journal Control and Intelligent Systems, DOI: 10.2316/Journal.201.2008.1.201-1820, Vol 36, No. 1, 2008

[7] M. Blanke, M. Kinnaert, J. Lunze and M. Staroswiecki, Diagnosis and Fault Tolerant Control, Springer, 2003

[8] A. Cervin, D. Henriksson, B. Lincoln, J. Eker and K. Arzén, How Does Control Timing Affect Performance?, IEEE Control Systems Magazine, Vol. 23, pp. 16-30, 2003

[9] T. Frank, K. F.-Kraiss and T. Kuhlen, Comparative Analysis of Fuzzy ART and ART-2A Network Clustering Performance, IEEE Transactions on Neural Networks, Vol. 9, No. 3, May 1998

[10] D. Hanselman and B. littlefield, Mastering MATLAB, Prentice Hall, 2002 
[11] R. I.-Zamanabadi and M. Blanke, A Ship Propulsion System as a Benchmark for FaultTolerant Control, Control Engineering Practice, Vol. 7, pp. 227-239, 1999

[12] J. Jiang, and Q. Zhao, Reconfigurable Control Based on Imprecise Fault Identification, Proocedings of the American Control Conference, IEEE, pp. 114-118, San Diego, June, 1999

[13] F. Lian, J. Moyne and D. Tilbury, Network Design Consideration for Distributed Control Systems, IEEE Transactions on Control Systems Technology, Vol. 10, No. 2, pp. 297-307, March 2002

[14] L. Liu, Real-time Systems, Wiley, 2002

[15] Menendez L. de C. A. and H. Benítez-Pérez, Node Availability for Distributed Systems considering processor and RAM utilization Based upon a Local Optimization Procedure, INT J COMPUT COMMUN, ISSN 1841-9836, 5(3):336-350, 2010

[16] J. Nilsson, Real-Time Control with Delays, PhD. Thesis, Department of Automatic Control, Lund Institute of Technology, Sweden, 1998.

[17] H. Thompson, Wireless and Internet Communications Technologies for monitoring and Control, Control Engineering Practice, vol. 12, pp. 781-791, 2004

[18] D. Driankov, H. Hellendoorn and M. Reinfrank, An Introduction to Fuzzy Logic Control, Springer-Verlag, 1994

[19] L. Zhang, Y. Shi, T. Chen and B. Huang, A New Method for Stabilization of Networked Control Systems with Random Delays, American Control Conference, pp. 633-637, 2005

[20] D. Kim, D. Choi and P. Mohapatra, Real-Time Scheduling method for Networked Discrete Control Systems, Control Engineering Practice, Vol 17, pp: 564-570, 2009

[21] http://www.quanser.com/english/html/solutions/

fs_soln_software_wincon.html

[22] Zmaranda D., Gabor G., Popescu D.E., Vancea C., Vancea F., Using Fixed Priority Preemptive Scheduling in Real-Time Systems, INT J COMPUT COMMUN, ISSN 1841-9836, $6(1): 187-195,2011$

[23] Dai L., Chang Y., Shen Z.,An Optimal Task Scheduling Algorithm in Wireless Sensor Networks, INT J COMPUT COMMUN, ISSN 1841-9836, 6(1):101-112, 2011

[24] Negoita C.V., Remembering the Beginnings, INT J COMPUT COMMUN, ISSN 1841-9836, 6(3):458-461, 2011

[25] Nyirenda C.N., Dong F., Hirota K., Distance Based Triggering and Dynamic Sampling Rate Estimation for Fuzzy Systems in Communication Networks, INT J COMPUT COMMUN, ISSN 1841-9836, 6(3):462-472, 2011 